Profit Sharing (with workers) Facilitates Collusion (among firms)

\author{
Dan Bernhardt \\ Christopher Chambers
}

W. Allen Wallis Institute of Political Economy

Working Paper No. 22

June 2001 


\title{
Profit Sharing (with workers) Facilitates Collusion (among firms)
}

\author{
Dan Bernhardt ${ }^{1} \quad$ Christopher Chambers ${ }^{2}$ \\ University of Illinois University of Rochester
}

June 13, 2001

${ }^{1} 463$ Wohlers Hall, University of Illinois, Champaign, Illinois 61820, danber@uiuc.edu

${ }^{2}$ Department of Economics, University of Rochester, Rochester NY 14627 


\title{
Profit Sharing (with workers) Facilitates Collusion (among firms)
}

\begin{abstract}
This paper shows how profit sharing by firms with workers always facilitates increased collusion among firms in a dynamic oligopoly environment with uncertain demand. Expected firm profits are increased both if worker wages are tied to market conditions, or if workers instead receive a share of firm profits. We first show that firm profits are always increased by tying wages to market conditions. The optimal profit-sharing agreement generally features only partial profit sharing, because profit sharing raises the expected price-wage differential, but reduces price-wage variability. The attraction of profit-sharing agreements with workers is even greater. Indeed, we show that for any cartel size, there are always market conditions for which expected firm profits are increased simply by transferring some expected profit to workers, through the impact of this transfer on the incentive to cheat on the cartel.
\end{abstract}




\section{Introduction}

This paper addresses a basic contracting issue: How does the sharing of profits between a firm and its employees affect the ability of firms to support collusive oligopoly pricing and oligopoly profits? We explore this question in the dynamic oligopoly environment with uncertain demand first characterized by Julio Rotemberg and Garth Saloner (1986).

We obtain a stark answer: Profit sharing between firms and their employees always facilitates collusion between firms in the output market, raising expected firm profits. Indeed, we show that expected profits can even be raised by giving workers a share of firm profits, without extracting a corresponding reduction in wages. However, the optimal profit sharing agreement features only partial profit sharing, so that, along the equilibrium path, net firm profit rises monotonically with the demand realization.

It is important to emphasize that our findings do not revolve around either worker moral hazard or insurance explanations. In our barebones economy there is no problem eliciting efficient worker effort; profit sharing is not required to overcome worker moral hazard. Further, all parties are risk neutral, so there is no role for insurance.

Rather, the driving economic force is that profit sharing between workers and firms favorably impacts on the strategic interaction of firms in the output market. The economics underlying our results can be gleaned from recalling equilibrium outcomes in Rotemberg and Saloner (1986). There, firms repeatedly interact in an economy with independently and identically distributed demand shocks. Because expected future collusive profits do not depend on the period demand shock, but the gains from cheating on the cartel rise with period demand, firms can support monopoly profits only if the demand shock is sufficiently low. If demand is too high, then total industry output is increased beyond the monopoly level just until firms cease to have an incentive to cheat on the cartel.

In this environment, consider the impact of tying worker compensation to market conditions. Incentive compatible profit sharing with workers effectively lowers worker compensation in low demand states, and raises worker compensation in high demand states. But it is in the low demand states where firms do not have an incentive to cheat on the cartel, so that in these low demand states greater firm profits are then realized due to the lower worker 
compensation. In contrast, in sufficiently high demand states, firm profit is completely unaffected by increased worker compensation, as profit is already constrained by the heightened incentive to cheat on the cartel.

The optimal profit sharing agreement generally features only imperfect profit sharing because while profit sharing increases the expected price-worker compensation difference, it also reduces the variance of this difference. Since the period profit function is convex, as profit sharing is increased, eventually expected firm profits decline (unless it is the case in the Rotemberg and Saloner environment that monopoly profits cannot be sustained even for the lowest demand realization). However, since the variance has only a second order impact on firm profits, but raising the expected price-worker compensation difference has a first order impact on firm profits, it follows that some profit sharing is always optimal.

We first consider an environment in which there is not explicit profit sharing between firms and workers, but suppose that workers' wages can be tied to market conditions in a linear fashion, so that wages are higher when market demand is higher. This framework highlights the tradeoff of increased profit sharing on (i) the expected price-wage difference and (ii) the variance of the price-wage difference. In this environment, we show that incentive compatible profit sharing between firms and workers always allows firms to capture increased profit. This result has the more general implication that the optimal wage contracts for firms are not independent of demand.

We then explicitly allow for profit sharing, so that employees can receive a share of firm profits. Here another benefit of profit sharing on the incentive of a firm to cheat on the cartel is revealed: If a firm cheats by increasing output and hence profits, it must (i) hire more workers to produce the output, and (ii) pay higher compensation to each worker because its profits are higher. Consequently, an explicit profit sharing agreement with workers reduces a firm's incentive to cheat on a cartel. To highlight this latter feature, we provide sufficient conditions under which firms can increase expected profits simply by giving their employees a share of firm profits, without demanding a lower wage in return. We show that for a cartel of any size, there exist market conditions such that giving workers a share of firm profits is optimal; the reduction in the incentive to cheat on the cartel supported by this transfer to workers supports monopoly pricing in enough additional higher demand states to more than 
offset the transfer of surplus to employees.

\section{The Model}

The basic framework is that of Rotemberg and Saloner (1986): $n$ firms producing a homogeneous good repeatedly interact in an infinite horizon economy with stochastic demand. Period market demand at time $t$ is given by

$$
D_{t}\left(\theta_{t}, P_{t}\right)=\theta_{t}-P_{t}
$$

where $\theta_{t}$ is an independently and identically distributed demand shock, with distribution function $F$ on its positive support, $[\underline{\theta}, \bar{\theta}] .{ }^{1}$ The risk neutral firms share common discount factor $\beta \in(0,1)$, and compete in prices in the output market.

Because we want to study the impact of profit sharing between workers and firms, we have to model the production function of a firm more explicitly than do Rotemberg and Saloner. We assume that one hour of labor is required to produce one unit of the good. Workers are risk neutral, and have an outside opportunity of $\bar{\omega}$ per hour, which, without loss of generality, we normalize to zero.

Absent profit sharing, our framework corresponds to Rotemberg and Saloner. Firms support maximal period profits by threatening to revert to marginal cost pricing if any firm ever deviates from the collusive pricing agreement. Let $\Pi^{m}(\theta)=\left(\frac{0-\bar{w}}{2}\right)^{2}$ denote monopoly profits if the demand shock is $\theta$, and let $V$ represent expected period profit per firm along the equilibrium path in which firms co-operate. Along a co-operative path, firms split total profit equally. Given a demand shock $\theta$, monopoly profits are sustainable if and only if

$$
\left(\frac{\Pi^{m}(\theta)}{n}\right)+\left(\frac{\beta}{1-\beta}\right) V \geq \Pi^{m}(\theta)
$$

That is, incentive compatibility mandates that the expected profits from continued cooperation (the left hand side), exceed the one-time gains from cheating on the cartel by lowering price slightly to capture the entire market profit (the right hand side). The following proposition formalizes this intuition, where $\Pi^{s}(\theta)$ is sustainable profit in state $\theta$.

\footnotetext{
${ }^{1}$ None of our results qualitatively depend on the independently and identically distributed nature of the demand shocks. Demand shocks could follow a Markov process, or there could be cycles in demand as in John Haltiwanger and Joseph Harrington (1991).
} 
Proposition 1 (Rotemberg and Saloner) Suppose that monopoly profits can be sustained in some demand states, but not in others. That is, there exists a $\theta^{*} \in(\underline{\theta}, \bar{\theta})$ which solves

$$
\left(\frac{\beta}{1-\beta}\right)\left[\int_{\underline{\theta}}^{\theta^{*}} \Pi^{m}(\theta) F(d \theta)+\left(1 \dot{-} F\left(\theta^{*}\right)\right) \Pi^{m}\left(\theta^{*}\right)\right]=(n-1) \Pi^{m}\left(\theta^{*}\right) \text {. }
$$

Then optimal pricing strategies support monopoly profits in demand states $\theta \geq \theta^{*}$, but only support profits of $\Pi^{m}\left(\theta^{*}\right)$ in higher demand states $\theta>\theta^{*}$ :

$$
\Pi^{s}(\theta)=\left\{\begin{array}{cc}
\Pi^{m}(\theta), & \theta \leq \theta^{*} \\
\Pi^{m}\left(\theta^{*}\right), & \theta>\theta^{*}
\end{array} .\right.
$$

In particular, along the equilibrium path, for low demand states $\theta \leq \theta^{*}$, firms set prices equal to the monopoly price of $\frac{\theta}{2}$, and each firm produces $\frac{\theta}{2 n}$. For higher demand realizations, $\theta>\theta^{*}$, firms set price at $\frac{\theta^{*}}{2}$, less than the monopoly level. Higher prices cannot be sustained in these high demand states, as firms would have an incentive to cheat on them to garner the entire market profit.

\subsection{Profit sharing: Demand-linked wage contracts}

We first explore how outcomes are affected when worker compensation is tied to market conditions. Each period, before any demand shock is realized, firms and workers can sign binding wage agreements, in which the wage depends on the market shock. For simplicity, we focus on linear wage contracts,

$$
\omega\left(\theta_{t}, a_{t}^{i}\right)=\omega\left(a_{t}^{i}\right)+a_{t}^{i}\left(\theta_{t}-E(\theta)\right)
$$

Here, $a_{t}^{i}$ is a firm specific variable which weights the difference between the current demand state and the expected demand state, and $\omega\left(a_{t}^{i}\right)$ is the fixed component of compensation that does not depend on the demand shock. The wage contracts signed at each firm are public information.

Incentive compatibility mandates that workers expect to beat their reservation alternative when signing the wage contract:

$$
\int_{\underline{\theta}}^{\bar{\theta}}\left(\omega\left(a_{t}^{i}\right)+a_{\ell}^{i}(\theta-E(\theta))\right) Q\left(\theta, a_{t}^{i}\right) F(d \theta) \geq \int_{\underline{\theta}}^{\bar{\theta}} \bar{\omega} Q\left(\theta, a_{t}^{i}\right) F(d \theta) .
$$

Here, $Q\left(\theta, a_{t}^{i}\right)$ is a function detailing the total quantity of labor hired when the demand realization is $\theta$ and the wage contract parameter is $a_{t}^{i}$. For the moment, take $Q\left(\theta, a_{t}^{i}\right)$ to be 
increasing in $\theta$. If $a_{t}^{i}=0$, then $\omega\left(\theta_{t}, a_{t}^{i}\right)=\bar{\omega}$. However, if $a_{t}^{i} \in(0,1)$, then because (i) worker compensation is higher in high demand states, and (ii) firms produce more output in these high demand states (where workers beat their reservation alternative), the firm can lower the fixed component of wages, $\omega\left(a_{t}^{i}\right)$, and the wage contract will still be incentive compatible. Finally, if $a_{t}^{i}=1$, then the firm is 'fully-insured' against the demand shock, so that its output level (in a symmetric equilibrium in which all firms choose $a_{t}^{i}=1$ ) will not vary with market conditions, so that again $\omega\left(\theta_{t} ; a_{t}^{i}\right)=\bar{\omega}$.

After the wage contract is signed, the period demand shock is realized. Upon observing the demand shock, given the history of past demand shocks, wage contracts and past price selection, firms simultaneously decide on prices. That is, each firm's strategies are a sequence of functions $\left\{\left(a_{t}^{i}, P_{t}^{i}\right)\right\}$ where $a_{t}^{i}$ maps histories of length $t-1$ into wage contracts, and $P_{t}^{i}$ maps from histories of length $t-1$ together with $\left(a_{t}, \theta_{t}\right)$ into a price selection.

Before proceeding with our analysis, we first note that the assumption that firms and workers can sign binding period wage contracts is made only for simplicity; our findings extend when binding contracts cannot be signed. When binding contracts can be signed, in equilibrium, firms extract all surplus in wage negotiations, so that a worker's ex ante incentive compatibility constraint will hold at equality. Then, ex post, if $\theta_{t}$ is sufficiently low, workers will regret signing the binding wage contract. However, to retrieve ex post incentive compatibility for workers even in the lowest demand state $\underline{\theta}$, firms only need to give workers a slightly higher fixed wage component, $w\left(a_{i}^{i}\right)$, and threaten never to hire a worker who rejects a wage offer. Section 2.2 offers a more complete characterization of ex post incentive compatible profit sharing.

Our analysis focuses on symmetric equilibrium paths; so, from now on, without loss of generality, we drop the index $i$ from strategies. We look at firm trigger strategies in which if any firm has deviated in the past from the specified symmetric wage contract and pricing choices, then each firm sets price equal to marginal cost in the future. Such strategies support maximal firm profits.

Along a symmetric action path, period market profit, $\Pi_{t}\left(\theta_{t}, P_{t}\right)$, is given by

$$
\Pi_{t}=\left(\theta_{t}-P_{t}\right)\left(P_{t}-\left(\omega\left(a_{t}\right)+a_{t}\left(\theta_{t}-E(\theta)\right)\right)\right) .
$$

Along the equilibrium path, firms choose the wage contract parameter, $a_{t}$, and period price 
function $P\left(a_{t}, \theta_{t}\right)$, to maximize the sum of discounted expected profits subject to the constraint that the wage contract be incentive compatible for workers. Since the optimal wage contract parameter will not vary with time, we denote it simply by $a$, and let

$$
\Pi^{m}(\theta, a)=\left(\frac{\theta+a(E(\theta)-\theta)-\omega(a)}{2}\right)^{2}
$$

denote monopoly profits as a function of demand shock and wage contract parameter, $a$. We consider symmetric equilibrium outcomes in which each firm produces an identical amount of output, splitting profits equally.

As in Rotemberg and Saloner, the expected profit-maximizing strategy profile along the equilibrium path consists of a pricing schedule such that there exists some $\theta^{*}(a)$ for which each firm uses monopoly pricing for $\theta \leq \theta^{*}(a)$, and prices so that period profits are just equal to $\Pi^{m}\left(\theta^{*}(a), a\right)$ for $\theta>\theta^{*}(a)$. Off the equilibrium path, firms choose prices that generate zero profit.

Denoting these sustainable profits as a function of demand shock and wage contract by $\Pi^{s}(\theta, a)$, we have

$$
\Pi^{s}(\theta, a)= \begin{cases}\Pi^{m}(\theta, a), & \theta \leq \theta^{*}(a) \\ \Pi^{m}\left(\theta^{*}(a), a\right), & \theta>\theta^{*}(a)\end{cases}
$$

Therefore, the expected profits for any given firm under these strategies are:

$$
(1 / n) \sum_{t=0}^{\infty} \beta^{t} E\left[\Pi^{s}(\theta, a)\right]
$$

The equilibrium level of $a^{*}$ maximizes these profits (where the worker incentive compatibility constraint is now implicit). Our first proposition details that in equilibrium, as long as firms cannot support monopoly profits in the Rotemberg and Saloner environment in every demand state, then it is always beneficial for firms to tie worker compensation to market conditions:

Theorem 1 If $\theta^{*}(0)<\bar{\theta}$, so that monopoly profits cannot be supported in all demand states, then firms optimally tie worker compensation to the demand realization, setting $a^{*}>0$.

Since we show that the optimal linear wage contract features tied wages, an immediate corollary is that the optimal unconstrained wage contract also features wages that are nontrivially tied to demand. 


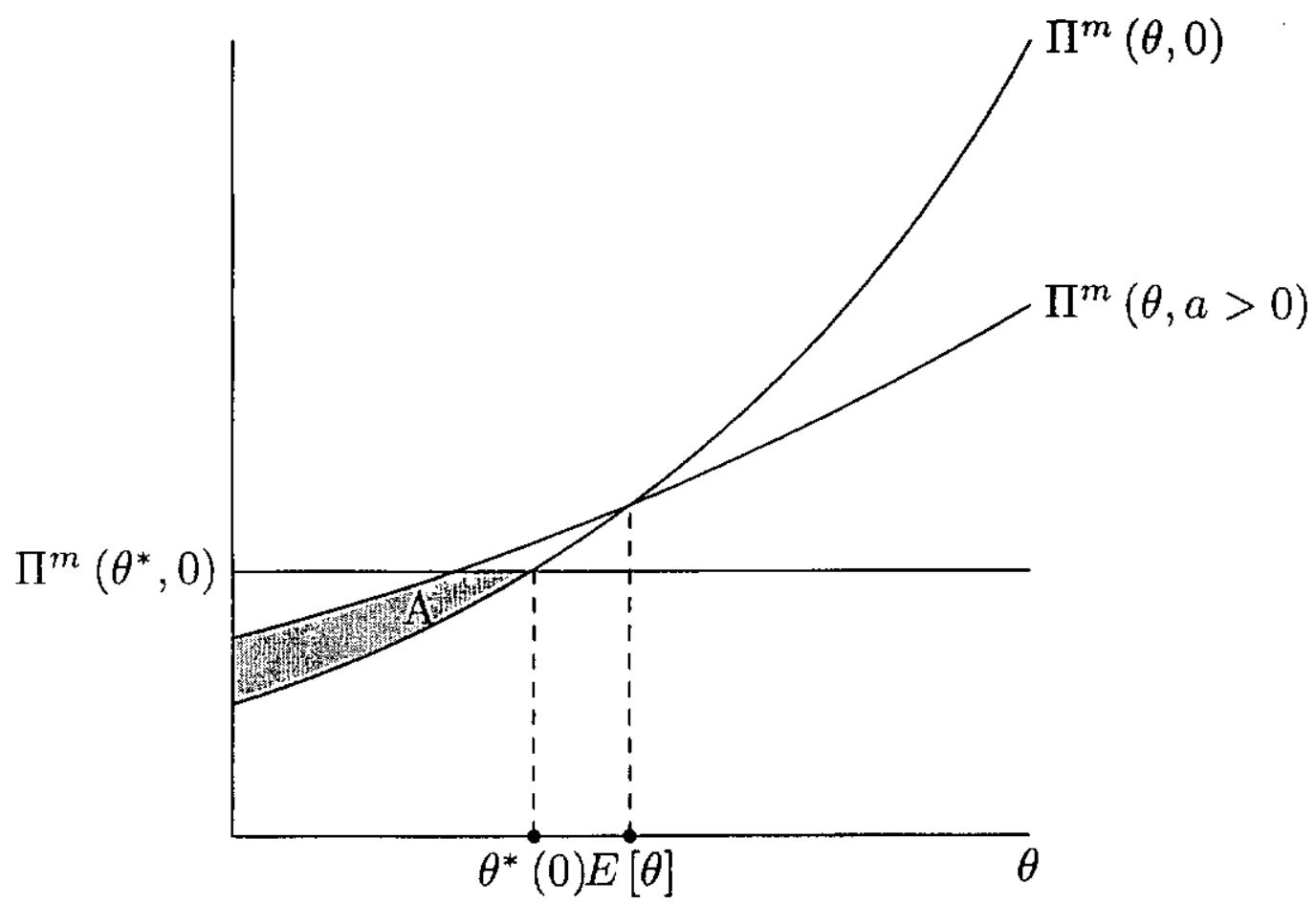

Figure 1: Change in Expected Profits when $\theta^{*}(0)<E[\theta]$.

To understand Theorem 1, consider a version of the model in which firms do not extract lower fixed wage concessions in return for demand sensitive wages, so that the wage is $\bar{w}+a\langle\theta-E[\theta])$. Since firms produce more when demand is higher, such wage contracts transfer some of the surplus generated by increased collusion to workers, reducing the profitability of tying wages to market conditions. Consider first Figure 1, which contrasts period monopoly profits when firms do not tie wages to market conditions, $\Pi^{m}(\theta, 0)$, with monopoly profits when they do, $\Pi^{m}(\theta, a>0)$. Note that the two profit levels are equal if $\theta=E[\theta]$, so that $\bar{w}+a(\theta-E[\theta])=\bar{w}$. Figure 1 depicts the case where if wages are not tied to market conditions, then the maximal demand state that supports monopoly profits, $\theta^{*}(0)$, is less than $E[\theta]$. In particular, this implies that period monopoly profits are not sustainable for demand shocks exceeding $E[\theta]$; for all $\theta \geq \theta^{*}(0)$, maximal sustainable profits are just $\Pi\left(\theta^{*}(0), 0\right)$. In sharp contrast, using the same continuation payoffs, if $a>0$, greater collusive profits can be supported for all $\theta<\theta^{*}(0)$, and there is no offsetting reduction in period profits for $\theta>\theta^{*}(0)$. The profit increase from tying wages to market conditions corresponds to the shaded area $A$ in the diagram. Further, since expected period profits are increased, continuation payoffs must also be greater, so that more collusive pricing can be supported even if $\theta>\theta^{*}(0)$. Indeed, 


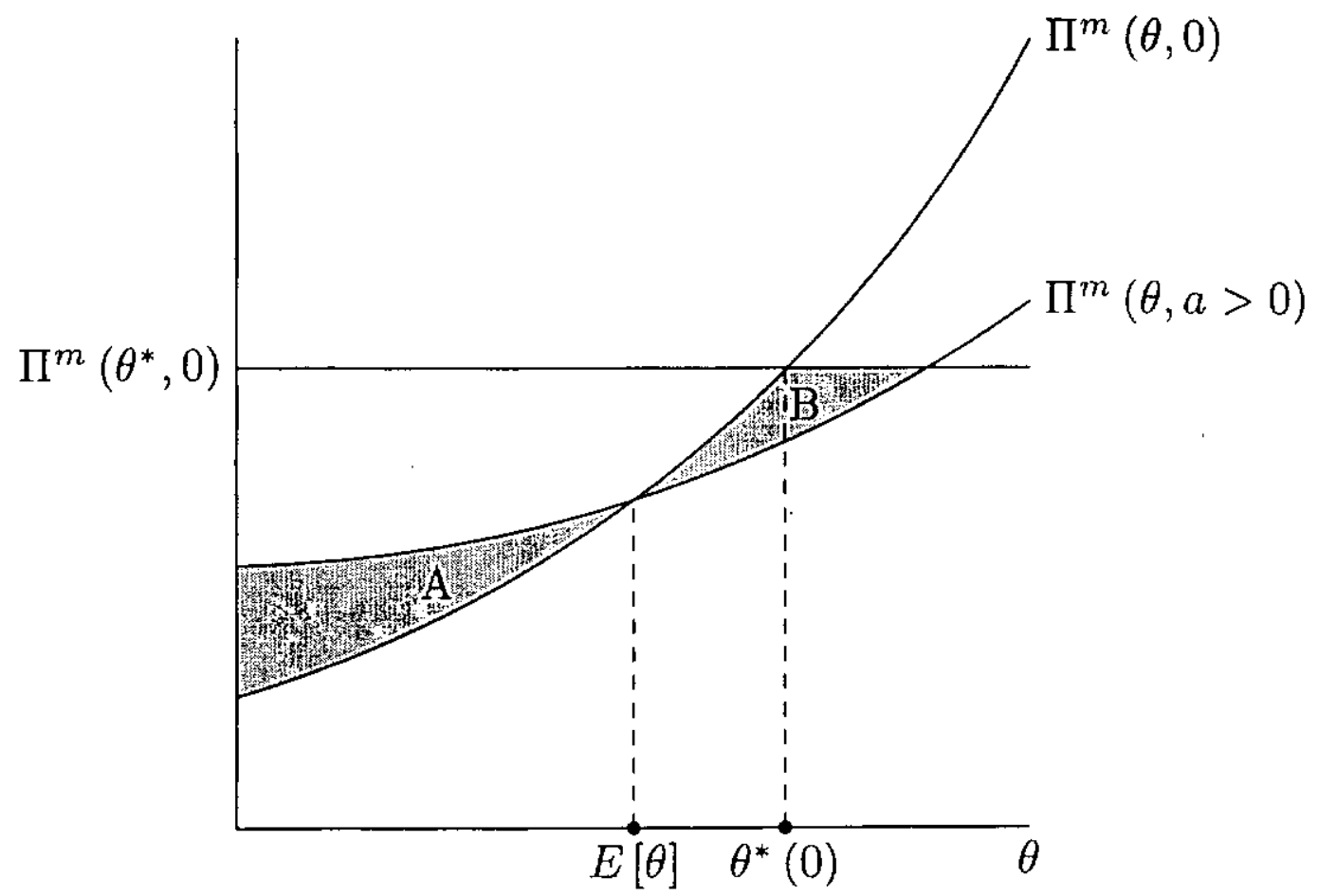

Figure 2: Change in Expected Profits when $\theta^{*}(0)>E[\theta]$.

the reason that tying wages perfectly to market conditions, i.e. setting $a=1$, is not optimal is that eventually, monopoly profits can be supported for demand realizations $\theta>E[\theta]$, creating a cost to tying wages to market conditions.

Figure 2 illustrates this second case, where $\theta^{*}(0)>E(\theta)$. Here, by tying wages to demand firms gain profit in low demand states (shaded area $A$ ), but lose profit in high demand states (shaded area $B$ ). If $B>A$, then it is better not to tie wages to market conditions at all than to tie them to the degree that $B>A$.

What the proof of theorem 1 does is show that when firms extract all surplus in contracting from workers, expected firm profits are always increased by slightly tying wages to market conditions, i.e. by choosing an $a>0$ that is sufficiently small. Since $u(a)<\bar{w}$, the expected price-wage differential is greater when wages are tied to the demand realization. However, the variance of the price-wage differential is reduced. Since the profit function is convex, reducing this variance reduces expected profits. But, since the increase in the mean of the price-wage differential has a first order impact on expected profits, whereas the reduction in its variance has a second order impact, it follows that slightly tying wages to market 
conditions is always optimal.

Formally, we show in the appendix that

$$
\begin{aligned}
\frac{\partial}{\partial a} E\left[\Pi^{s}(\theta, a)\right]_{\left.\right|_{\alpha=0}} & =\int_{\underline{\theta}}^{\theta^{*}(0)} \theta\left(\frac{E(\theta)-\theta-\left.\frac{\partial \omega(a)}{\partial a}\right|_{a=0}}{2}\right) F(d \theta) \\
& >\int_{\underline{\theta}}^{\bar{\theta}} \theta\left(\frac{E(\theta)-\theta-\left.\frac{\partial \omega(a)}{\partial a}\right|_{a=0}}{2}\right) F(d \theta) \\
& >\frac{1}{2} \int_{\underline{\theta}}^{\bar{\theta}} \theta\left(E(\theta)-\theta-\frac{\int_{\underline{\theta}}^{\bar{\theta}}(E(\theta)-\theta)(\theta / 2) F(d \theta)}{\int_{\underline{\theta}}^{\bar{\theta}}(\theta / 2) F(d \theta)}\right) F(d \theta)=0,
\end{aligned}
$$

where $\Pi^{s}(\theta, a)$ in this expression is the sustainable level of period one profit when after period one, all firms use the Rotemberg and Saloner equilibrium $(a=0)$.

In general, significant tying of wages to market conditions may be optimal. Figure 3 illustrates how the optimal degree to which wages should be tied to market conditions varies with $\theta^{*}(0)$, the highest demand realization for which monopoly profits can be supported. Note that $\theta^{*}(0)$, which rises with the discount factor $\beta$ and falls with number of firms, $n$, is a sufficient statistic for the primitives describing the economy. Figure 3 illustrates the optimal wagetying rule when the demand shock is uniformly distributed on $[1,10]$. As collusion becomes sustainable in more demand states, the degree to which wages should be tied to market conditions declines. That is, a cartel that can sustain monopoly profits in very high demand states has more to lose by signing wage tying contracts with workers than a cartel that cannot. Observe that perfectly tying wages to market conditions is optimal only when, in the absence of tying wages to market conditions (i.e. in the Rotemberg and Saloner environment), the cartel cannot sustain monopoly profits even in the worst demand state.

\subsection{Binding wage contracts}

We now return to our earlier discussion regarding the robustness of our results to relaxing the assumption that wage contracts are binding. Consider now an environment in which workers are infinitely lived, with common discount factor $\gamma \in(0,1)$, and that after the demand shock is realized, workers make a decision whether or not to abide by the wage agreement. Firms could then use strategies which threaten to not hire a worker in the future if the worker ever chooses not to abide by the wage contract terms. Firms must now augment the fixed wage 


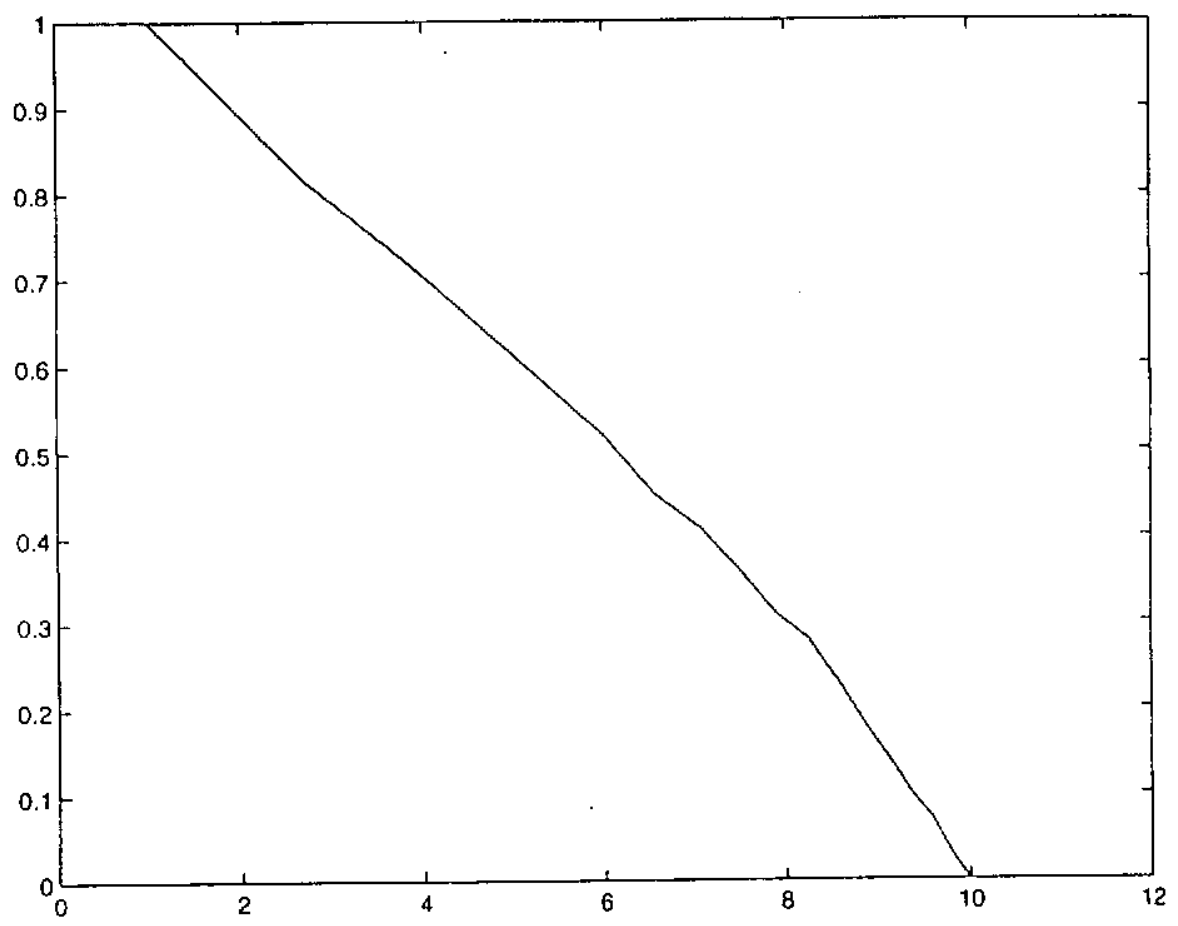

Figure 3: Optimal wage-tying parameter $a$ as a function of $\theta^{*}(0)$

component to $\omega(a)+\epsilon(a)$, where $\epsilon(a)$ provides workers just enough expected surplus from the future worker-firm relationship to ensure that it is incentive compatible ex post for workers to supply their labor. Ex post incentive compatibility requires that the workers willingly accept the wage contract even in the worst demand state, $\underline{\theta}$,

$$
(\omega(a)+\epsilon(a)+a(\underline{\theta}-E(\theta)))\left(\frac{\theta}{2}\right)+\left(\frac{\gamma}{1-\gamma}\right) \int_{\underline{\theta}}^{\bar{\theta}}(\omega(a)+\epsilon(a)+a(\theta-E(\theta))) Q(\theta, a) F(d \theta) \geq 0
$$

where the right-hand side reflects the normalization, $\bar{\omega}=0$.

For any given $\epsilon(a)>0$, this relationship is always satisfied for all $\gamma$ sufficiently close to one. Indeed, if workers are arbitrarily patient, firms can obtain ex-ante incentive compatibility of workers by offering a vanishingly small fixed wage increase, $\epsilon(a) \rightarrow 0$. In turn, this implies that our analysis extends immediately. More generally, if workers are more impatient, then firms must offer workers a greater share of the surplus from tying wages to market conditions. In this case, tying wages to market conditions raises expected collusive firm profits only if, in the absence of tying wages, it is sufficiently difficult to support monopoly profits, i.e., if $\theta^{*}(0)$ is sufficiently small relative to the other parameters characterizing the economy. 


\subsection{Pure Profit Sharing}

It is straightforward to show that if, rather than tying wages to market conditions, firms share profits and extract the lowest incentive compatible fixed wage in return, it is always optimal for firms to share some of their profits with their workers. This leads us to pose a more ambitious question, asking under which conditions can firms raise profits by actually giving a share of profits back to workers, without demanding any wage concessions? The structure of the economy is the same as before, save that we now assume that one worker produces one unit of good. The period $t$ compensation given to workers is $\bar{w}+a_{t} \Pi_{t}\left(\theta_{t}\right)$, where

$$
\Pi_{t}=\left(\theta_{t}-P_{t}\right)\left(P_{t}-\bar{w}\right)
$$

where $a_{t}$ is the profit sharing rule, and the demand shock is $\theta_{t}$. Incentive compatibility for workers is not an issue, as period profits are always positive. We again maintain the assumption that $\bar{w}$ is normalized to zero.

We study symmetric equilibria in which for any $a$, firms use optimal pricing whenever sustainable. To support such pricing, upon deviation by any firm, firms use marginal cost pricing. Letting $V$ denote the expected period profits along the equilibrium path from colluding, we see that optimal profits (denoted here by $\Pi^{*}$ ) in period zero are sustainable for state $\theta$ given profit sharing level $a$ when

$$
\frac{(1-a L(\theta, a)) \Pi^{*}(\theta)}{n}+\left(\frac{\beta}{1-\beta}\right) V \geq(1-a n L(\theta, a)) \Pi^{*}(\theta)
$$

Here, $L(\theta, a)$ is the total number of workers needed per firm to produce the profit maximizing output. The left hand side of the above inequality represents expected discounted profits from continued collusion. Profits per firm are $\Pi^{*}(\theta) / n$, but each firm gives a share of $a L(\theta, a)$ away to workers, according to the profit-sharing agreement. Continued cooperation in the current period implies that the expected discounted future payoffs are then- $\frac{\beta}{1-\beta} V$.

A firm that deviates from the cartel agreement optimally does so by marginally undercutting the price set by others. If a firm deviates it can obtain as much of the entire market as it desires. If the deviating firm meets the entire market demand, it can earn a profit of $\Pi^{*}(\theta)$, but it must return a share $\operatorname{an} L(\theta, a)$ back to its employees. Because the firm must hire more workers to produce the entire market output, not only must each worker be paid more if it 
cheats on the cartel, the firm must also pay more workers. In turn, this reduces the attraction of cheating on the cartel. It is for this reason that simply signing contracts that give workers a share of firm profits can raise expected cartel profits, a form of 'addition by subtraction'.

The following result then obtains.

Theorem 2 Suppose that the demand shock, $\theta$, is uniformly distributed on $[\underline{\theta}, \bar{\theta}]{ }^{2}$ Then a sufficient condition for expected cartel profits to be raised by giving workers a share of profits, i.e. setting $a^{*}>0$, is

$$
\begin{gathered}
{\left[2(n+1) \bar{\theta} \theta^{*}(0)-(2 n+1) \theta^{*}(0)^{2}-\bar{\theta}^{2}-\bar{\theta} \sqrt{\bar{\theta}^{2}-\theta^{*}(0)^{2}}+\theta^{*}(0)^{2} \log \left(\frac{\bar{\theta}+\sqrt{\bar{\theta}^{2}-\theta^{*}(0)^{2}}}{\theta^{*}(0)}\right)\right]} \\
>\frac{\theta^{*}(0)^{4}-\underline{\theta}^{4}}{2 \theta^{*}(0)^{2}}
\end{gathered}
$$

where $\theta^{*}(0)$ is the maximal demand shock such that monopoly profits can be supported in the absence of profit sharing (i.e. in the Rotemberg and Saloner environment). In particular, (i) for any $n$, given $\underline{\theta}$ if $\theta^{*}(0)-\underline{\theta}$ and $\bar{\theta}$ - $\underline{\theta}$ are sufficiently small, firms can raise expected cartel profits by giving workers a share of profits,

(ii) for any $(\underline{\theta}, \bar{\theta}, \beta)$, there exists a $n(\underline{\theta}, \bar{\theta}, \beta)$ such that for all $n \geq n(\underline{\theta}, \bar{\theta}, \beta)$, profit sharing is optimal, and

(iii) for any $(\underline{\theta}, n)$, there exists a $\ddot{\theta}(\underline{\theta}, n)$ such that for any $\bar{\theta}<\bar{\theta}(\underline{\theta}, n)$ there exists a $\beta^{*}(\underline{\theta}, \bar{\theta}, n)<1$ such that for any $\beta \leq \beta^{*}(\underline{\theta}, \bar{\theta}, n)$, profit sharing is optimal.

The proof proceeds by finding conditions under which firms can support greater expected cartel profits simply by giving workers a very small share, $a$, of those profits, rather than setting $a=0$. In the neighborhood of $a=0$, firms optimally set price equal to the monopoly price whenever the monopoly price can be supported, and if a firm decides to deviate from the cartel agreement, it optimally supplies the entire market. For larger profit-sharing rules, firms price in excess of the monopoly price whenever possible, choosing price to maximize residual profits retained by firms, $(1-a L)(\theta-L) L$, with associated optimal price, $\frac{2 a \theta-1+\sqrt{a^{2} \theta^{2}-a \theta+1}}{3 a}$.

\footnotetext{
${ }^{2}$ The uniform assumption is made only to simplify the characterization.
} 
While raising price above the monopoly level reduces total profit, it also reduces the number of workers hired, which, in turn, increases the net profits that cartel members actually retain. For similar reasons, if $a$ is substantially greater than zero, a deviating firm would choose to ration some of the market, rather than meet the entire market by hiring the necessary number of workers. Thus, Theorem 2 provides a sufficient, but not necessary condition, for net cartel profits to be raised by giving workers a share of profits.

The intuition underlying part (ii) of Theorem 2 is that as $n$ rises, $\theta^{*}(0)$ decreases, so that the gain to sharing profits is larger. Moreover, each firm employs fewer workers so that the profit that each firm returns to its workforce declines, while a deviating firm must return the same entire market profit back to its workforce, independently of $n$. Figures 4-6 shows how the marginal impact on expected period profits induced by sharing a marginal amount of profits with workers varies with $\theta^{*}(0)$ for $n \in\{2,4,10\}$ when the demand shock is uniformly distributed on the interval $[0,10]$. For these parameter values, (i) when there are two firms, marginal profit sharing is never optimal; (ii) if there are four firms, marginal profit sharing is only optimal for intermediate values of $\theta^{*}$; and (iii) if there are ten or more firms, marginal profit sharing is optimal unless $\theta^{*}$ is very large, in which case period monopoly profits can almost always be supported even in the absence of profit sharing.

\section{Conclusion}

This paper offers an explanation for the prevalence of profit-sharing agreements between workers and firms. Importantly, our explanation revolves around neither moral hazard, nor risk sharing. Rather, we show that profit-sharing agreements between workers and firms can facilitate collusion among firms in the output market. We highlight two features of profitsharing agreements: (a) profit sharing ties worker compensation to market conditions, so that worker compensation is higher when demand is higher, and (b) if, to cheat on the cartel, the firm must hire more workers, then the firm must return a greater portion of those profits back to workers, reducing the attraction of cheating on the cartel.

We first show that it is always optimal to tie worker compensation to market conditions. Tying compensation to market conditions raises the expected price-wage differential, but reduces its variance. Since raising the expected price-wage differential has a first order impact 


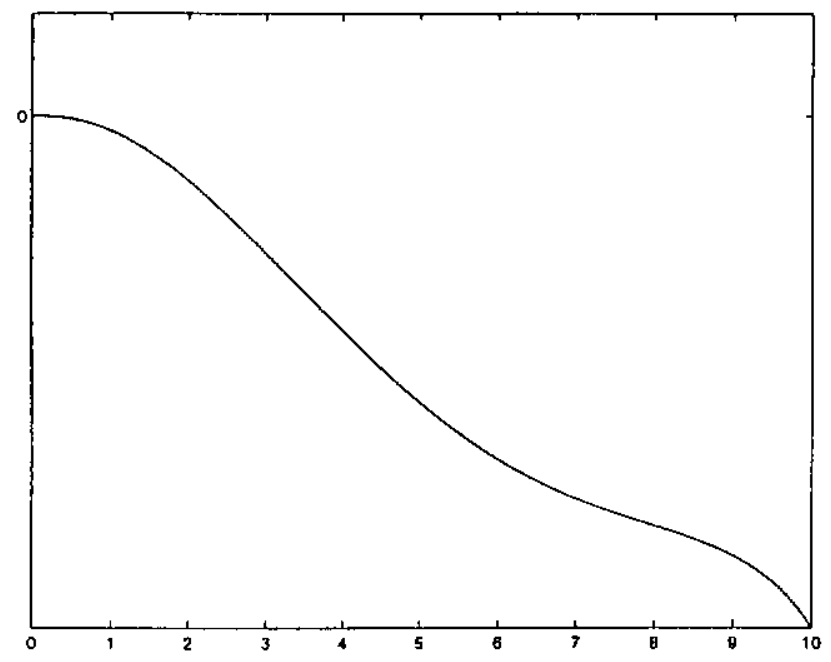

Figure 4: $n=2$

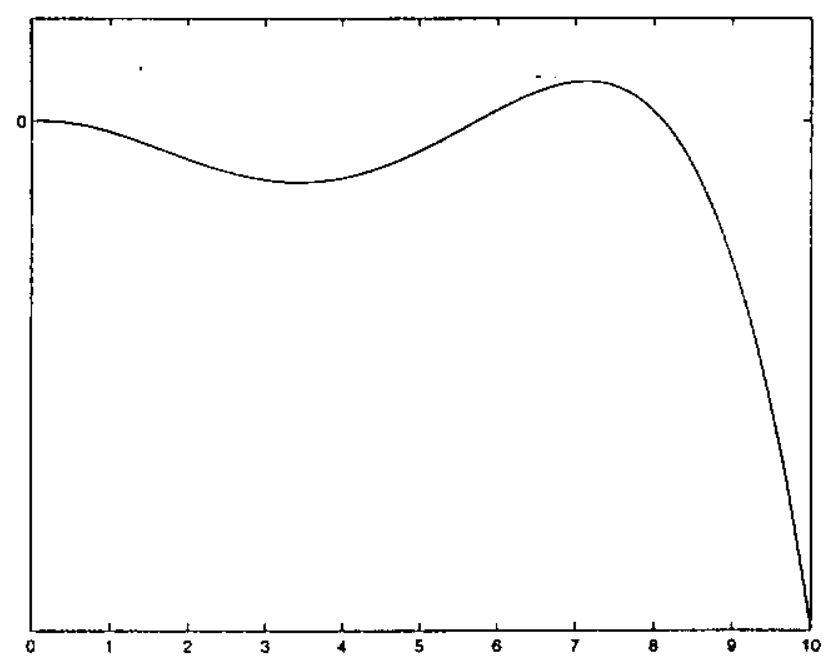

Figure 5: $n=4$

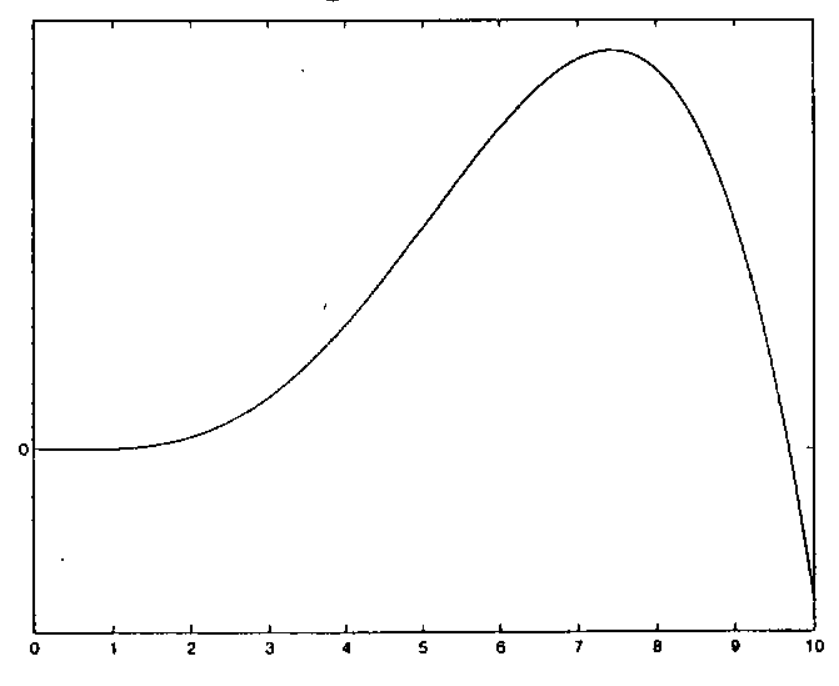

Figure 6: $n=10$ 
on expected profits, but reducing its variance has only a second order impact on profits, it follows that it is always optimal to tie compensation to market conditions at least to some limited extent. We illustrate that while it is not optimal to perfectly tie worker compensation to market conditions, significant tying remains optimal.

We then focus on how the incentives to cheat on the cartel are affected if, to do so, a firm must hire more workers. A powerful and striking result obtains: For any cartel size, there are always market conditions for which firms can increase expected profits simply by giving workers a share of the profits that the firm earns. That is, the increased ability to collude in the output market more than offsets the reduced profit share that the firm receives.

The bottom line is that stock options and other profit sharing agreements may do more than provide workers the incentive to work hard; they may help firms support collusively higher prices in the output market. 


\section{Appendix}

Proof of Theorem 1: We first consider strategies in which after the initial period, firms use strategies which require zero profit sharing, but otherwise, support optimal payoffs. We show that even with these sub-optimal strategies, that wages should be tied to market conditions in period 1. Thus, we let $K=E\left[\Pi^{s}(\theta, 0) / n\right]$, as above. In this appendix, $\Pi^{s}(\theta, a)$ refers to the sustainable level of profits in period one given these strategies when demand is $\theta$, and $a$ is chosen.

Let $Q(\theta, a)$ denote the associated optimal period one quantity produced when the demand shock is $\theta$,i.e. the output level that supports $\Pi^{s}(\theta, a)$ :

$$
Q(\theta, a)=\left\{\begin{array}{ll}
(\theta / 2) & \theta \leq \theta^{*}(a) \\
\left(\theta+\sqrt{\theta^{2}-\theta^{*}(a)^{2}}\right) / 2 & \theta>\theta^{*}(a)
\end{array} .\right.
$$

where $\theta^{*}(a)$ is an implicit function of $K$, solving

$$
\Pi^{m}\left(\theta^{*}(a), a\right)=\left(\frac{n}{n-1}\right)\left(\frac{\beta}{1-\beta}\right) K .
$$

The worker's incentive compatibility constraint is

$$
\int_{\underline{\theta}}^{\bar{\theta}}(\omega(a)+a(\theta-E(\theta))) Q(\theta, a) F(d \theta)=\int_{\underline{\theta}}^{\bar{\theta}} \bar{\omega} Q(\theta, a) F(d \theta) .
$$

The left hand side of the equality is what workers obtain by working at the wage structure; the right hand side is what they get if they use their labor to obtain their outside opportunity. In equilibrium, this constraint holds as an equality as firms will never choose $\omega(a)$ any higher than necessary.

We prove the theorem using a sequence of lemmas.

Lemma 1 At $a=0$,

$$
\frac{\partial \omega(a)}{\partial a}=\frac{\int_{\underline{\theta}}^{\bar{\theta}}(E(\theta)-\theta) Q(\theta, 0) F(d \theta)}{\int_{\underline{\theta}}^{\bar{\theta}} Q(\theta, 0) F(d \theta)} .
$$

Proof: Recall, as $\bar{\omega}=0$,

$$
\int_{\underline{\theta}}^{\bar{\theta}}(\omega(a)+a(\theta-E(\theta))) Q(\theta, a) F(d \theta)=0 .
$$


This expression establishes that $\omega(0)=0$. Differentiating each side of the equality with respect to $a$ obtains:

$$
\int_{\underline{\theta}}^{\bar{\theta}}\left(\frac{\partial \omega(a)}{\partial a}+\theta-E(\theta)\right) Q(\theta, a)+\frac{\partial Q(\theta, a)}{\partial a}(\omega(a)+a(\theta-E(\theta))) F(d \theta)=0 .
$$

When evaluated at $a=0$, the above expression becomes:

$$
\frac{\partial \omega(a)}{\partial a}=\frac{\int_{\underline{\theta}}^{\bar{\theta}}(E(\theta)-\theta) Q(\theta, 0) F(d \theta)}{\int_{\underline{\theta}}^{\bar{\theta}} Q(\theta, 0) F(d \theta)}
$$

Lemma 2 At $a=0$,

$$
\frac{\partial}{\partial a} E\left[\Pi^{s}(\theta, a)\right]=\int_{\underline{\theta}}^{\theta^{*}(0)} \theta\left(\frac{E(\theta)-\theta-\left.\frac{\partial \omega(a)}{\partial a}\right|_{a=0}}{2}\right) F(d \theta)
$$

Proof: Note that

$$
E\left[\Pi^{s}(\theta, a)\right]=\int_{\underline{\theta}}^{\theta^{-}(a)}\left(\frac{\theta+a(E(\theta)-\theta)-\omega(a)}{2}\right)^{2} F(d \theta)+\int_{\theta^{*}(a)}^{\vec{\theta}}\left(\frac{n}{n-1}\right)\left(\frac{\beta}{1-\beta}\right) K F(d \theta) .
$$

By Leibnitz' rule, we obtain

$$
\begin{aligned}
& \frac{\partial E\left[\Pi^{s}(\theta, a)\right]}{\partial a}=\int_{\underline{\theta}}^{\theta^{*}(a)} \frac{\partial}{\partial a}\left(\frac{\theta+a(E(\theta)-\theta)-\omega(a)}{2}\right)^{2} F(d \theta) . \\
& =\int_{\underline{\theta}}^{\theta^{*}(a)}(\theta+a(E(\theta)-\theta)-\omega(a))\left(\frac{E(\theta)-\theta-\frac{\partial \omega(a)}{\partial a}}{2}\right) F(d \theta) .
\end{aligned}
$$

Evaluating at $a=0$,

$$
=\int_{\underline{\theta}}^{\theta^{*}(0)} \theta\left(\frac{E(\theta)-\theta-\left.\frac{\partial \omega(a)}{\partial a}\right|_{a=0}}{2}\right) F(d \theta)
$$

The above lemma guarantees that $\left.\frac{\partial}{\partial a} E\left[\Pi^{s}(\theta, a)\right]\right|_{a=0}>0$ if $\theta^{*}(0) \leq E(\theta)-\left.\frac{\partial \omega(a)}{\partial a}\right|_{a=0}$.

The rest of the proof considers the case where $\theta^{*}(0)>E(\theta)-\left.\frac{\partial \omega(a)}{\partial a}\right|_{a=0}$.

\section{Lemma 3}

$$
\int_{\underline{\theta}}^{\bar{\theta}} \theta\left(\frac{E(\theta)-\theta-\left.\frac{\partial \omega(a)}{\partial a}\right|_{a=0}}{2}\right) F(d \theta)<\int_{\underline{\theta}}^{\theta^{*}(0)} \theta\left(\frac{E(\theta)-\theta-\left.\frac{\partial \omega(a)}{\partial a}\right|_{a=0}}{2}\right) F(d \theta) .
$$


Proof: We note that

$$
E(\theta)-\left.\frac{\partial \omega(a)}{\partial a}\right|_{a=0}=\frac{\int_{\underline{\theta}}^{\bar{\theta}} \theta Q(\theta, 0) F(d \theta)}{\int_{\underline{\theta}}^{\bar{\theta}} Q(\theta, 0) F(d \theta)}>0
$$

Moreover, note that the expression

$$
\theta\left(\frac{E(\theta)-\theta-\left.\frac{\partial \omega(a)}{\partial a}\right|_{a=0}}{2}\right)
$$

is quadratic, taking zeroes at $\theta=0$ and $\theta=E(\theta)-\left.\frac{\partial \omega(a)}{\partial a}\right|_{a=0}$. The expression is strictly negative to the right of $E(\theta)-\left.\frac{\partial \omega(a)}{\partial a}\right|_{a=0}$. Therefore, the conclusion follows.

The next lemma guarantees that the increase in the fixed wage component is less than it would be if collusion were sustainable in all states of demand.

\section{Lemma 4}

$$
\left.\frac{\partial \omega(a)}{\partial a}\right|_{a=0}=\frac{\int_{\underline{\theta}}^{\bar{\theta}}(E(\theta)-\theta) Q(\theta, 0) F(d \theta)}{\int_{\underline{\theta}}^{\bar{\theta}} Q(\theta, 0) F(d \theta)} \leq \frac{\int_{\underline{\theta}}^{\bar{\theta}}(E(\theta)-\theta)(\theta / 2) F(d \theta)}{\int_{\underline{\theta}}^{\bar{\theta}}(\theta / 2) F(d \theta)} .
$$

Proof: Suppose the wage tying parameter is $a^{\prime}>0$. The right hand side of the expression in the statement of the lemma is the change in the fixed component of the wage under perfect monopoly pricing. Denote this fixed component of the wage under perfect monopoly pricing by $\omega_{M}\left(a^{\prime}\right)$. The right hand side of the inequality is $\left.\frac{\partial \omega_{M}(a)}{\partial a}\right|_{a=0}$. Note that $\omega(0)=\omega_{M}(0)=0$. We will show that

$$
\int_{\underline{\theta}}^{\bar{\theta}}(\theta / 2)\left(a^{\prime}(\theta-E(\theta))+\omega\left(a^{\prime}\right)\right) F(d \theta)<0 .
$$

The left hand side of the inequality is the expected wage workers would receive were monopoly pricing used in all states, and workers were offered contracts. with fixed wage component $\omega\left(a^{\prime}\right)$.

This will enable us to show $\omega_{M}\left(a^{\prime}\right)>\omega\left(a^{\prime}\right)$. As $a^{\prime}$ is arbitrary, this establishes that at $a=0$,

$$
\frac{\partial \omega(a)}{\partial a} \leq \frac{\partial \omega_{M}(a)}{\partial a}
$$


as required. The incentive compatibility constraint for workers is:

$$
\int_{\underline{\theta}}^{\vec{\theta}}\left(Q\left(\theta, a^{\prime}\right)\right)\left(a^{\prime}(\theta-E(\theta))+\omega\left(a^{\prime}\right)\right) F(d \theta)=0 .
$$

Separating:

$$
\begin{gathered}
\int_{\underline{\theta}}^{\theta^{*}\left(a^{\prime}\right)}(\theta / 2)\left(a^{\prime}(\theta-E(\theta))+\omega\left(a^{\prime}\right)\right) F(d \theta)+\int_{\theta^{*}\left(a^{\prime}\right)}^{\bar{\theta}}(\theta / 2)\left(a^{\prime}(\theta-E(\theta))+\omega\left(a^{\prime}\right)\right) F(d \theta) \\
+\int_{\theta^{*}\left(a^{\prime}\right)}^{\bar{\theta}}\left(\sqrt{\theta^{2}-\theta^{*}\left(a^{\prime}\right)^{2}} / 2\right)\left(a^{\prime}(\theta-E(\theta))+\omega\left(a^{\prime}\right)\right) F(d \theta)=0 .
\end{gathered}
$$

We claim that

$$
\int_{\underline{\theta}}^{\theta^{*}\left(a^{\prime}\right)}(\theta / 2)\left(a^{\prime}(\theta-E(\theta))+\omega\left(a^{\prime}\right)\right) F(d \theta)<0 .
$$

If not, it is easy to see that

$$
\int_{\theta^{*}\left(a^{\prime}\right)}^{\bar{\theta}}(\theta / 2)\left(a^{\prime}(\theta-E(\theta))+\omega\left(a^{\prime}\right)\right) F(d \theta) \geq 0
$$

which in turn implies

$$
\int_{\theta^{*}\left(a^{\prime}\right)}^{\bar{\theta}}\left(\sqrt{\theta^{2}-\theta^{*}\left(a^{\prime}\right)^{2}} / 2\right)\left(a^{\prime}(\theta-E(\theta))+\omega\left(a^{\prime}\right)\right) F(d \theta)>0 .
$$

This follows as the last expression clearly weights higher values of $\theta$ at a larger ratio than the first expression through the use of $\left(\sqrt{\theta^{2}-\theta^{*}\left(a^{\prime}\right)^{2}} / 2\right)$ as opposed to $(\theta / 2)$. Summing the three inequalities obtains

$$
\int_{\underline{0}}^{\bar{\theta}}(Q(\theta))\left(a^{\prime}(\theta-E(\theta))+\omega\left(a^{\prime}\right)\right) F(d \theta)>0
$$

a contradiction. As

$$
\int_{\underline{\theta}}^{\theta^{*}\left(a^{\prime}\right)}(\theta / 2)\left(a^{\prime}(\theta-E(\theta))+\omega\left(a^{\prime}\right)\right) F(d \theta)<0,
$$

it must be that

$\int_{\theta^{*}\left(a^{\prime}\right)}^{\bar{\theta}}(\theta / 2)\left(a^{\prime}(\theta-E(\theta))+\omega\left(a^{\prime}\right)\right) F(d \theta)+\int_{\theta^{*}\left(a^{\prime}\right)}^{\bar{\theta}}\left(\sqrt{\theta^{2}-\theta^{*}\left(a^{\prime}\right)^{2}} / 2\right)\left(a^{\prime}(\theta-E(\theta))+\omega\left(a^{\prime}\right)\right) F(d \theta)>0$.

However, again, this inequality implies that

$$
\int_{\theta^{*}\left(a^{\prime}\right)}^{\bar{\theta}}\left(\sqrt{\theta^{2}-\theta^{*}\left(a^{\prime}\right)^{2}} / 2\right)\left(a^{\prime}(\theta-E(\theta))+\omega\left(a^{\prime}\right)\right) F(d \theta)>0
$$


The preceding inequality is exactly

$$
\int_{\underline{\theta}}^{\bar{\theta}}(Q(\theta)-\theta / 2)\left(a^{\prime}(\theta-E(\theta))+\omega\left(a^{\prime}\right)\right) F(d \theta)>0 .
$$

Separating, we see

$$
\int_{\underline{\theta}}^{\bar{\theta}}(Q(\theta))\left(a^{\prime}(\theta-E(\theta))+\omega\left(a^{\prime}\right)\right) F(d \theta)>\int_{\underline{\theta}}^{\bar{\theta}}(\theta / 2)\left(a^{\prime}(\theta-E(\theta))+\omega\left(a^{\prime}\right)\right) F(d \theta)
$$

where the left hand side of the inequality is zero. Hence, we have established that $\omega_{M}\left(a^{\prime}\right)>$ $\omega\left(a^{\prime}\right)$ for any $a^{\prime}>0$; moreover, then

$$
\omega_{M}\left(a^{\prime}\right)-\omega_{M}(0)>\omega\left(a^{\prime}\right)-\omega(0)
$$

establishing that at $a=0$,

$$
\frac{\partial \omega_{M}(a)}{\partial a} \geq \frac{\partial \omega(a)}{\partial a}
$$

Finally, our theorem demonstrates that firms can always achieve higher expected sustainable profits by tying wages to market conditions. We show this by establishing that at $a=0$,

$$
\frac{\partial}{\partial a} E\left[\Pi^{s}(\theta, a)\right]>0
$$

Proof: Suppose false. Then

$$
\left.\frac{\partial}{\partial a} E\left[\Pi^{s}(\theta, a)\right]\right|_{a=0} \leq 0
$$

The preceding lemmas taken together then imply that

$$
\int_{\underline{\underline{\theta}}}^{\bar{\theta}} \theta\left(\frac{E(\theta)-\theta-\left.\frac{\partial \omega(a)}{\partial a}\right|_{a=0}}{2}\right) F(d \theta)<0
$$

and

$$
\int_{\underline{\underline{0}}}^{\bar{\theta}} \theta\left(\frac{E(\theta)-\theta-\frac{\int_{\underline{\theta}}^{\bar{\theta}}(E(\theta)-\theta)(\theta / 2) F(d \theta)}{\int_{\underline{\underline{\theta}}}^{\bar{\theta}}(\theta / 2) F(d \theta)}}{2}\right) F(d \theta)<0 .
$$

Thus, we see that

$$
\int_{\underline{\theta}}^{\bar{\theta}}-\theta^{2}+\frac{\theta \int_{\underline{\theta}}^{\bar{\theta}} \theta^{2} F(d \theta)}{\int_{\underline{\theta}}^{\bar{\theta}} \theta F(d \theta)} F(d \theta)<0
$$


and thus

$$
-E\left[\theta^{2}\right]+E[\theta]\left(\frac{E\left[\theta^{2}\right]}{E[\theta]}\right)<0
$$

However, this is an obvious contradiction, as the expression above is identically zero.

Thus, we have shown that in period one, it is never optimal to set $a=0$. This analysis extends to future periods, as the problem for firms is time separable. Further, since period profits are increased by wage tying, it follows that continuation profits would be increased if there is wage tying in each period. In turn, increased continuation profits supports (weakly) more collusive output levels for all demand realizations, further increasing the profitability of tying wages to market conditions.

Proof of Theorem 2: We show that under the conditions detailed in the theorem that setting $a>0$ is optimal even when (i) firms produce the monopoly level of output, where-ever possible in the first period, and (ii) as in the proof of the theorem 1, there is a reversion after the first period to the strategies that do not feature profit sharing, and correspond to those in Rotemberg and Saloner. Fixing continuation payoffs to correspond to the Rotemberg and Saloner monopoly pricing equilibrium, for any $a$, we may solve for $\theta^{*}(a)$, as the $\theta^{*}$ which solves

$$
\left(1-a n L\left(\theta^{*}, a\right)\right) \Pi^{m}\left(\theta^{*}, a\right)=\frac{\left(1-a L\left(\theta^{*}, a\right)\right) \Pi^{m}\left(\theta^{*}\right)}{n}+K,
$$

where $K=E\left[\Pi^{s}(\theta) / n\right]$ is the expected period profit for any given firm. To simplify notation, we write $\theta^{*}$, leaving the dependence on $a$ implicit. Differentiating both sides of the above equality with respect to $a$ and evaluating at $a=0$ obtains:

$$
\frac{\partial \Pi^{m}\left(\theta^{*}\right)}{\partial \theta^{*}} \frac{\partial \theta^{*}}{\partial a}-n \Pi^{m}\left(\theta^{*}\right) L\left(\theta^{*}, a\right)=\frac{-L\left(\theta^{*}, a\right) \Pi^{m}\left(\theta^{*}\right)+\frac{\partial \Pi^{m}\left(\theta^{*}, a\right)}{\partial \theta^{*}} \frac{\partial \theta^{*}}{\partial \alpha}}{n} .
$$

Rearranging yields

$$
\frac{\partial \Pi^{m}\left(\theta^{*}\right)}{\partial \theta^{*}} \frac{\partial \theta^{*}}{\partial a}=(n+1) \Pi^{m}\left(\theta^{*}\right) L\left(\theta^{*}, a\right)
$$

Recall that expected period profits for the cartel given profit sharing level $a$ are

$$
\int_{\underline{\theta}}^{\theta^{*}}(1-a L(\theta, a)) \Pi^{m}(\theta) F(d \theta)+\int_{\theta^{*}}^{\bar{\theta}}(1-a L(\theta, a)) \Pi^{m}\left(\theta^{*}\right) F(d \theta) .
$$


Differentiating this expression with respect to $a$, and evaluating at $a=0$ yields:

$$
\int_{\underline{\theta}}^{\theta^{*}}-L(\theta, a) \Pi^{m}(\theta) F(d \theta)+\int_{\theta^{*}}^{\bar{\theta}}-L(\theta, a) \Pi^{m}\left(\theta^{*}\right)+\frac{\partial \Pi^{m}\left(\theta^{*}\right)}{\partial \theta^{*}} \frac{\partial \theta^{*}}{\partial a} F(d \theta) .
$$

We establish when this function takes positive values, or (solving) when

$$
\int_{\underline{\theta}}^{\theta^{*}}-L(\theta, a) \Pi^{m}(\theta) F(d \theta)+\int_{\theta^{*}}^{\bar{\theta}} \Pi^{m}\left(\theta^{*}\right)\left[(n+1) L\left(\theta^{*}, a\right)-L(\theta, a)\right] F(d \theta)
$$

is strictly positive. Substituting for $L(\theta, a)$ and $\Pi^{m}(\theta)$, as derived in the demand-linked wage contracts case and normalizing, yields the following expression:

$$
\frac{\theta^{4}-\theta^{* 4}}{4}+(1 / 2) \theta^{* 2}\left[2(n+1) \bar{\theta} \theta^{*}-(2 n+1) \theta^{* 2}-\bar{\theta}^{2}-\bar{\theta} \sqrt{\bar{\theta}^{2}-\theta^{* 2}}+\theta^{* 2} \log \left(\frac{\bar{\theta}+\sqrt{\bar{\theta}^{2}-\theta^{* 2}}}{\theta^{*}}\right)\right] \text {. }
$$

Rearranging, we see that this expression is positive if:

$$
\left[2(n+1) \bar{\theta} \theta^{*}-(2 n+1) \theta^{* 2}-\bar{\theta}^{2}-\bar{\theta} \sqrt{\bar{\theta}^{2}-\theta^{* 2}}+\theta^{* 2} \log \left(\frac{\bar{\theta}+\sqrt{\overline{\theta 2}-\theta^{* 2}}}{\theta^{*}}\right)\right]>\frac{\theta^{* 4}-\underline{\theta}^{4}}{2 \theta^{* 2}} .
$$

When this expression is positive, expected period one profits can be raised by signing profit sharing contracts with workers, and using a monopoly pricing scheme. We see that continuation payoffs must also be driven up, as the analysis applies at all periods. Therefore, we conclude that all firms setting $a=0$ is not optimal.

To see that (i) holds, note that at $\theta^{*}(0)=\bar{\theta}=\underline{\theta}$, both sides of (4) are equal to zero, but differentiating the left-hand side with respect to $\bar{\theta}$ yields $(2 n) \bar{\theta}>0$, while the derivative of the right-hand side is zero.

To see that (ii) holds, note that the derivative of (4) with respect to $\bar{\theta}$ evaluated at $\bar{\theta}$ when $\theta^{*}=\underline{\theta}$ is equal to $2(n+1) \theta^{*}-2 \theta-2\left(\theta^{2}-\theta^{* 2}\right)^{1 / 2}$. Therefore, there exists $n$ large enough so that this expression is positive, for all $\theta \leq \bar{\theta}$. For such $n$, there thus exists a neighborhood of $\underline{\theta}$ such that for all $\theta$ in this neighborhood, (4) is satisfied. Let $n(\underline{\theta}, \bar{\theta}, \beta)$ be this $n$. As $n$ increases, we see that (4) is true for any $\theta^{*}$ for which it was previously true (a simple monotonicity argument establishes this). Moreover, as $n$ increases, $\theta^{*}$ decreases to zero. Therefore, the result holds.

Lastly, (iii) is a trivial corollary to part (i), as $\theta^{*}$ is an increasing function of $\beta$. 


\section{References}

[1] Haltiwanger, John and Joseph E. Harrington, "The impact of cyclical demand movements on collusive behavior." RAND Journal of Economics, Vol. 22, (1991) 89-106.

[2] Rotemberg, Julio J. and Garth Saloner, "A supergame-theoretic model of price wars during booms." American Economic Review, 76, (1986) 390-407. 